\title{
RUBEM FONSECA \\ E AS PUBLICAÇÕES DO NOVO SÉCULO
}

Leonardo Barros Medeiros (UCP)

leonardoletras@gmail.com

\section{Apresentação}

\author{
Tuas palavras antigas \\ deixei-as todas, deixei-as \\ junto com as minhas cantigas, \\ desenhadas na areia.
}

(Cecília Meireles)

O presente trabalho espera trazer para o debate acadêmico os escritos dos primeiros anos do século XXI de Rubem Fonseca buscando fazer um contraponto com a sua produção literária das quatro últimas décadas do século XX.

Podemos dizer que Rubem Fonseca instaura no Brasil a literatura pós-moderna em todas as suas características, dentre outras: a violência elevada aos extremos, a exploração da temática citadina, a fugacidade do sexo, a solidão dos personagens. Todas essas, são inseridas em maior intensidade nos contos e diluídas nos romances. Veremos detalhadamente no corpo da pesquisa como tais características apresentam-se.

A pesquisa torna-se significativa já pela investigação de indícios na obra fonsequiana que se manifestam continuamente. Sabemos que o autor é arredio a qualquer tipo de entrevista, logo não há um depoimento formal seguro para ser usado como fonte.

Para fazermos tal comparação e, principalmente, vislumbrar uma possível alteração do estilo fonsequiano, pretendemos iniciar este trabalho com uma minuciosa pesquisa sobre as características mais acentuadas da produção literária de Rubem Fonseca para que, logo após, possamos demonstrar na penúltima publicação as mudanças observadas. Vale ressaltar que faremos tudo isso respaldados em citações das obras e em teóricos que também estudam o referido autor. 
A finalidade desta pesquisa é buscar responder algumas questões inerentes ao esvaziamento das propostas pós-modernas e, ainda, salientar que há uma significativa mudança na produção literária fonsequiana. $\mathrm{O}$ que se justifica pelo fato de poucos estudiosos terem se debruçado sobre a análise da transformação temática pósmoderna.

Ao escolher Rubem Fonseca, debruçamo-nos sobre um vasto campo, porém pouco explorado, por ele ser um autor contemporâneo e, ainda, por estar em processo de produção - seu último romance data de novembro de 2009. Sobre a complexidade de se trabalhar com autores contemporâneos, Eco (2008) diz que "para o autor moderno as opiniões ainda são vagas e contraditórias e a nossa capacidade crítica é falseada pela falta de perspectiva e tudo se torna extremamente difícil" (p. 13).

É nesse difícil caminho que abordamos o presente trabalho.

Ao construir o trabalho, percebemos a necessidade de utilizar diversas obras de Rubem Fonseca para a exemplificação de pequenas hipóteses, como por exemplo, ao observar as características mais presentes da escrita fonsequiana. Para situar o leitor nesta pesquisa, faremos uma legenda das obras selecionadas de Fonseca para efetuar esta investigação:

\begin{tabular}{|l|l|}
\hline Livros de Rubem Fonseca & Legenda \\
\hline Ela e outras mulheres & EOM \\
\hline Feliz Ano Novo & FAN \\
\hline Histórias de Amor & HÁ \\
\hline Lúcia McCartiney & LMC \\
\hline O buraco na parede & OBP \\
\hline O Caso Morel & OCM \\
\hline O selvagem da Ópera & SO \\
\hline 64 contos de Rubem Fonseca & CRF \\
\hline
\end{tabular}

A escolha da amostra atendeu a critérios da diversidade temática e, em alguns casos, da ocorrência de alterações das características peculiares. Todavia, mais que qualquer critério, prevaleceu o interesse pela adequação do conteúdo em relação à presunção desenvolvida. 


\title{
2. Estudo crítico do autor: Rubem Fonseca e a ficção do cotidi- ano
}

\begin{abstract}
Nenhum escritor gosta realmente de escrever. Eu gosto de amar e de beber vinho: na minha idade eu não deveria perder tempo com outras coisas, mas não consigo parar de escrever. É uma doença. (Rubem Fonseca)
\end{abstract}

Rubem Fonseca não aparece na mídia, não tem foto no jornal, não dá entrevistas. Gosta do anonimato, preserva a sua intimidade e quando as pessoas o reconhecem nas ruas como escritor ele se apresenta com outro nome. Nascido em Juiz de Fora, formou-se em Direito e foi atuar como comissário de polícia no $16^{\circ}$ Distrito Policial, em São Cristóvão, no município do Rio de Janeiro. Em 1976, depois de ter vendido 30.000 exemplares de Feliz Ano Novo, foi censurado ${ }^{16}$ sob a alegação de que seu livro exteriorizava matéria contrária à moral e aos bons costumes, sendo assim, foi proibida a publicação e a circulação em todo o território nacional e, ainda, determinada a apreensão de todos os exemplares postos à venda. Esse fato ao contrário do pretendido pela censura, tornou o livro e, respectivamente, o autor bastante lido pela comunidade de leitores.

O trabalho como comissário de polícia proporcionou a Fonseca um amplo conhecimento sobre o cotidiano delinquente e esse ambiente é transmitido na sua produção literária. Sobre essa influência da vida de Rubem Fonseca na sua obra, Figueiredo (2003) diz que:

Principalmente nos contos escritos nas décadas de 60 e 70, a delegacia é um espaço privilegiado na ficção de Rubem Fonseca [...]. Os registros policiais são como fragmentos da realidade que remetem para um quadro mais geral no qual as perguntas ficam sem resposta. Pode-se, então, ler alguns contos do autor como páginas extraídas de um grande livro de ocorrências (p. 22).

O conto "Livro de Ocorrências", por exemplo, em que essa influência é perceptível a partir do nome, já apresenta analogia com o cotidiano de uma delegacia nessa narrativa, a trama é feita sobre três ocorrências que contêm elementos policiais:

${ }^{16}$ Censura publicada na Portaria de n 8.401-B, de 15 de dezembro de 1976. 
$\mathrm{O}$ investigador Miro trouxe a mulher à minha presença. Foi o marido, disse Miro. Naquela delegacia de subúrbio era comum briga de marido e mulher. Ela estava com dois dentes partidos na frente, os lábios feridos, o rosto inchado. Marcas nos braços e no pescoço (CRF; p. 254).

Como se pode perceber com o fragmento acima, Fonseca instaura em sua literatura uma peculiaridade no que tange à temática, que é a de, geralmente, ser formada por aspectos criminais, inaugurando a literatura urbana moderna no Brasil. Ora o cotidiano de uma delegacia, ora a violência de criminosos.

Nesse sentido, percebemos que a obra de Rubem Fonseca está inserida numa estética de tendência denunciadora da realidade chamada por uns teóricos de realismo feroz (Cf. MOISÉS, 2005; p. 587), de ultrarrealismo (Cf. CANDIDO, 1987; p. 210), ou de hiperrealismo (Cf. BARBIERI, 2003; p. 81), por outros de neorrealismo violento (Cf. BOSI, 2006; p. 423.) ou, ainda, de pseudorrealismo (Cf. FIGUEIREDO, 2003; p. 28.). Preferimos, aqui, enquadrá-lo tal qual a tese de Lajolo et Zilberman (2006) de estética do soco no estômago, nomenclatura que aglutina as tendências acima num determinado espaço de tempo da produção literária. A propósito dessa estética, as autoras revelam que:

O livro-soco no estômago resulta de uma tomada de posição por parte da literatura brasileira, que, desde a década de 30 , e talvez antes, com o Naturalismo do final do século XIX, foi assumindo crescentemente uma ótica social, voltada à revelação das mazelas do país. Nos anos 70 do século XX, essa tendência assumiu conotação anti-establishment: os padrões dominantes estavam fortemente relacionados à ditadura militar e à euforia desenvolvimentista (p. 55).

As autoras reforçam que essa tendência atual de se fazer literatura possui sua expressão mais completa nos livros de Rubem Fonseca, afirmando que a estética fonsequiana:

[...] discute a justiça social - ou sua falta - num meio que se moderniza e progride tecnologicamente, mas acirra as clivagens entre os grupos dominantes e os carentes de poder, levando estes últimos à marginalidade ou à revolta (Idem, p. 55).

Possuindo tal espírito para literatura, Rubem Fonseca escreve romances, contos, crônicas. Publicou Os prisioneiros (1963), A coleira do cão (1965), Lúcia McCartney (1967), O caso Morel (1973), Feliz Ano Novo (1975), O homem de fevereiro ou março (1973), O cobrador (1979), A grande arte (1983), Bufo \& Spallanzani (1986), 
Vasta emoções e pensamentos imperfeitos (1988), Agosto (1990), Romance negro e outras histórias (1992), O selvagem da ópera (1994), O buraco na parede (1995), Histórias de amor (1997), E do meio do mundo prostituto só amores guardei no meu charuto (1997), Confraria de espadas (1998), O doente Molière (2000), Secreções, excreções e desatinos (2002), Diário de um Fescenino (2003), Mandrake: a bíblia e a bengala (2006), Ela e outras mulheres (2006), O romance morreu (2007) e antologias reunindo seus contos. Realizou roteiros cinematográficos, tais como: "Relatório de um homem casado", "A extorsão", "Stelinha", "A grande arte", "Bufo \& Spallanzani". Por essa vasta publicação recebeu inúmeros prêmios literários, destacando o Prêmio Luís de Camões ${ }^{17}$, em 2003, pelo conjunto da obra. Sua produção literária recebeu adaptações para o teatro e televisão. Obteve traduções, dentre outras, para o inglês, francês, espanhol, alemão, sueco, italiano.

A produção de Rubem Fonseca é distinguida pela crítica e, mesmo que brevemente, estudada pela academia. Apresentamos aqui citações sobre a escrita de Rubem Fonseca. De um lado, Moisés (2005) afirma que Fonseca é "elevado à categoria de um dos nossos mais bem-dotados ficcionistas contemporâneos [...] e que desfruta hoje de um merecido renome nacional e internacional" (p. 588). Por outro lado, Martínez (2005) diz que "Nenhum escritor é mais cinematográfico que Fonseca. A passagem de uma cena a outra é feita sem explicações, de maneira natural" (p.10). Já Barbiere (2003) afirma: "Considero Rubem Fonseca, um dos escritores de maior repercussão nas últimas décadas, o protótipo do escritor inserido no mercado" (p. 29). Pelo seu êxito, o escritor é conhecido pela crítica como o maldito, conforme afirma Viegas (1996):

O sucesso, fato sociológico e estatístico, deve ser relacionado com a situação cultural em que a obra surge. Rubem Fonseca é um maldito que está em moda. Não vende aquilo que o público espera, mas oferece algo que o seu público esperava. Representa indivíduos malditos numa linguagem violenta, despida de metaforização (p. 132).

\footnotetext{
${ }^{17}$ O Prêmio Luís de Camões é considerado o "Nobel" da literatura em língua portuguesa, concedidos pelos governos do Brasil e Portugal.
} 
Outros dizem que escreve no domínio do medo, como é caso de Tomaz Eloy Martinez na introdução dos 64 contos de Rubem Fonseca:

Fonseca instala o medo ou o Mal no próprio interior da linguagem, cada uma de suas palavras é como uma nota musical arrancada da sinfonia do Mal. A exemplo dos poetas, ele faz as palavras tocarem a borda extrema de seus sentidos. Lendo-o sente-se o poder de dissuasão ou de perversão que até a mais surrada palavra pode comportar. Muito poucos conseguiram, como ele, criar um personagem com dois ou três traços, urgir tramas cujas costuras não se veem (FONSECA, 2005, p. 10).

Sobre Rubem Fonseca, Barbiere (2003) diz que:

Na ficção contemporânea brasileira, podem-se identificar várias maneiras que dão continuidade a tradição machadiana; mas dificilmente se encontrará, depois de Marques Rebelo e Nelson Rodrigues, outro da envergadura de Rubem Fonseca. Este soube penetrar, com agudo olhar, a complexidade da sociedade carioca, desvelando suas contradições, misérias e grandezas (p. 104).

A obra de Rubem Fonseca é conhecida pelo peculiar tom realista adotado na sua escrita, para Massaud (2005, p. 587), "realismo feroz, cruel, que não cede ante os gestos mais violentos ou as palavras de baixo calão". Segundo Bosi (2006), Rubem Fonseca segue a "linha do neorrealismo violento" sendo um explorador do "universo urbano e marginal" (p. 423). O mesmo Bosi afirma que:

Há os [autores] que submetem percepções e lembranças à luz da análise materialista clássica, dissecando os motivos, em geral perversos, dos comportamentos de seus personagens que ainda trazem a marca de tipos sociais. É o caso de Rubem Fonseca, que vem dos anos 60 e demonstrou força e fôlego nas páginas cruéis (p. 436).

A obra de Fonseca é banhada pela diversidade temática, abrangendo temas identificáveis, tais como o erotismo e a violência urbana. A seguir, propomos observar os frequentes recursos utilizados por Rubem Fonseca na sua criação literária.

Há na totalidade das obras de Rubem Fonseca características predominantes na temática, na escrita, na linguagem. Como disse Aristóteles na poética clássica, "A excelência da linguagem consiste em ser clara sem ser chã" (p. 43). Desse modo, Fonseca trabalha com a linguagem, aglutina outras situações e possibilidades, tudo para talhar sua obra para o literário. Uma das características é a forma como escreve suas obras apresentando uma linguagem enxuta e sem rodei- 
os Fonseca, dessa maneira, entra diretamente no cerne da questão abordada, como ressaltou Viegas (1996):

As narrativas de Rubem Fonseca, assim como de outros autores contemporâneos, têm como projeto recuperar um modo de contar, lançando mão de uma linguagem despida de metáforas ou eufemismos como recurso para falar do homem atual (p. 131).

Esse recurso linguístico, o da linguagem enxuta, adotado por Fonseca, pode ser exemplificado por meio do conto "Cidade de Deus", em que o autor narra a relação sexual de Zinho e Soraia de forma incisiva, em que não há nenhum pudor ao narrar o fato, nenhuma transferência de sentido para termos menos agressivos ou nenhum atenuante para suas ideias: "Foram para a cama. Zinho era rápido e rude e depois de foder a mulher virava as costas para ela e dormia. Soraia era calada e sem iniciativa" (HA; p. 11).

Sobre o efeito que essa linguagem seca provoca no leitor, Martinez diz que:

Tudo que leio de Fonseca produz em mim um assustador efeito de realidade. Ele escreve com a liberdade de um falcão, ou de um abutre, mas as palavras que desfia tecem um desenho do qual o leitor jamais consegue se desvencilhar, como acontece com as moscas capturadas pela voracidade da aranha (FONSECA, 2005; p. 14).

Sua descrição é realizada à base de pinceladas fortes no sentido em que relata os fatos de sua ficção, o que proporciona ao leitor inexperiente certo estranhamento ou, até mesmo, o faz suspender a leitura. A crueza é bastante acentuada no conto "Laurinha", em que o protagonista e o personagem Manoel torturam o estuprador e assassino da filha e sobrinha: a cena é transmita ao leitor sem nenhuma preocupação de não o chocar:

Agarrei os colhões de Duda e cortei lentamente, ouvindo os gritos lancinantes dele. Peguei o saco escrotal dele com os dois testículos e joguei na lata de lixo. [...] Em seguida, com as barras de ferro, quebramos os cotovelos, depois as costelas, depois a clavícula, sempre com um intervalo entre uma coisa e outra. Com um martelo parti todos os dentes dele. [...] O puto morreu coberto de merda, mijo e sangue (EOM, p. 9496).

Os diálogos que permeiam a trama são perfeitamente funcionais, pois promovem no leitor a contextualização necessária à compreensão do que é narrado. No conto "O caso de F. A.”, cuja história 


\section{FACULDADE DE FORMAÇÃo de PROFESSORES}

nos é mostrada por meio de diálogos, pode-se compreender melhor essa afirmação:

"Sou louco por mineira", disse para Magda, depois.

"Aqui não tem mineira nenhuma".

"Puxa, que azar. Só tem vocês quatro?" perguntei.

“Você gosta de variar, não é?" (LMC, p. 62).

Nesse conto em específico, o conteúdo total da narrativa só é apreendido por meio dos diálogos que o permeiam. É pela permanente conversa entre os personagens da trama que percebemos que o protagonista pretende resgatar uma prostituta novata do lugar onde ela mora.

Outra marca concreta na literatura de Fonseca é a presença da oralidade na sua escrita. Em "O caso de F. A.”, já citado aqui, o texto é todo dramatizado por meio de trinta diálogos face a face e de quatorze telefônicos, envolvendo cerca de vinte e cinco pessoas, durante apenas três dias. De sua estrutura narrativa aparecem apenas os verbos dicendi (respondeu, disse, respondi, perguntei), numa repetição característica da linguagem oral. le?"

"A cidade não é aquilo que se vê do Pão de açúcar. Na casa da Gise-

"Foi", respondeu F. A.

"Aquela francesa é mesquinha e ruim. E também uma trepada de merda. Dizem."

"Eu dou qualquer dinheiro", disse F. A.

"Hum", respondi.

"Você disse que o dinheiro compra tudo. Eu gasto o que for preciso", disse F. A.

"Sei. Continua" (LMC, p. 55).

O conto contém em sua totalidade mais diálogos do que narração. Sobre o conto, Urbano (2000) afirma que:

Acentua-se, pois, quantitativamente, a reprodução recriada da língua oral em situações de comunicação de variada natureza em diferentes momentos. A linguagem situacional, nesse sentido, aparece no diálogo 
com contato direto e imediato ou na conversa telefônica, onde há contato imediato, mas não face a face (p. 242).

Tal reprodução, também, pode ser notada pela fala da personagem Gisele, dona de um prostíbulo, que apresenta um sotaque francês, como se percebe pela vibração acentuada dos erres. O narrador indica a existência do sotaque no início do diálogo e, também, apresenta no texto a duplicação do erre para caricaturar a personagem.

"Alô". Um sotaque francês forte.

"Quem fala aqui é Paulo Mendes".

"Pardon, mas não sei de quem se trata".

"Sou amigo do Orlandino".

“Ah, oui, como está Orrlandim?".

"Ele está bem mandou um abraço para... a senhora".

"Muito obrigad" (LMC; p. 59).

Desse modo, a oralidade torna-se presente na obra fonsequiana, não só pelos elementos gráficos, tais como: a repetição de erres, o uso de interjeições, ou o uso de vocábulos obscenos, como também, pelos recursos gráficos: exclamação, interrogação, reticências.

Outra evidência, na narrativa fonsequina, do uso da oralidade é a presença de expressões do léxico próprio das camadas populares da sociedade e de vocábulos obscenos. Podemos exemplificar com: "gatuno", "a dona", "mulherio", "parrudo", "traseiro" (para nádegas), "quebrar o galho", "o raio da mulher", "o ovo no cu da galinha", "viado", "porra", "puta que pariu", "pra caralho", "filho da puta", dentre outros.

Abordaremos, a seguir, a temática da violência e do sexo presentes na literatura fonsequiana não a deixando por último ao acaso e sim, possivelmente, por se tratar das características mais relevantes da produção de Rubem Fonseca.

Sobre a violência na narrativa fonsequiana, Candido (1987) diz que:

Ele [Rubem Fonseca] também agride o leitor pela violência, não apenas dos temas, mas dos recursos técnicos - fundindo ser e ato na eficácia de uma fala magistral em primeira pessoa, propondo situações alter- 
nativas na sequência da narração, avançando as fronteiras da literatura no rumo de uma espécie de notícia crua da vida (p. 211).

Por causa dessa violência explícita que o livro de contos Feliz Ano Novo foi censurado. Sobre a censura, Figueiredo (2003) afirma que:

O alvo principal dos censores foi a tematização da sexualidade. Acusaram o autor de pornografia, de atentado à moral e aos bons costumes, e usaram como prova, o uso dos palavrões, enquanto o que de fato incomodava no livro e incomoda, ainda, é a variação, a cada conto, de pontos de vista sobre a violência levando o leitor a ver a realidade de diferentes ângulos (p. 28).

O alvo dos censores estava apontado corretamente para o propósito de Rubem Fonseca: o sexo e a violência. De todas as características pontuadas neste capítulo, percebe-se claramente que obra de Fonseca é sitiada pela violência e pelo sexo. De imediato trataremos de abordar a temática da violência e, por conseguinte, a do sexo. Começaremos citando um trecho de "O cobrador", para exemplificar como é trabalhada a temática da violência:

Ela estava grávida, ele disse apontando a mulher, vai ser o nosso primeiro filho. Olhei a barriga da mulher esguia e decidi ser misericordioso e disse, puf, em cima de onde achava que era o umbigo dela, desencarnei $\log$ o feto. A mulher caiu emborcada. Encostei o revólver na têmpora dela e fiz ali um buraco de mina (CRF, p. 278).

Podemos, também, visualizar esta temática presente no trecho do conto "Jéssica":

Agarrei Jéssica pelos cabelos e comecei a esmurrar o rosto dela. Quebrei primeiro o seu nariz, depois o maxilar, depois a boca, fazendo os dentes saltarem para fora, em seguida quebrei os ossos que ficam debaixo dos olhos, e arrebentei os ossos das orelhas (EOM; p. 67).

A violência em Rubem Fonseca não possui forma única, ela é trabalhada de todos os ângulos possíveis, sobre diversas óticas. Tal violência é manifestada por meio da linguagem, da escrita, da descrição das cenas, dos diálogos, das intervenções realizadas pelo narrador. Viegas (1996) afirma que: "Rubem Fonseca vitaliza o assunto da violência, apesar do desgaste sofrido a partir da nossa convivência diária com a própria violência" (p. 132). Assim, age com frieza o personagem de "Passeio Noturno" e "Passeio Noturno II", ambos contos de Feliz Ano Novo (1993), para distrair-se de um dia tumultuado ele atropela as pessoas nas ruas por sadismo. 
Outro exemplo marcante dessa linguagem violenta se dá por meio do próximo modelo, retirado do conto "O anão" de $O$ buraco na parede (1995).

Agarrei o anão pelo pescoço e levantei ele no ar e ele se debateu e me fez cambalear pela sala batendo nos móveis até cairmos no chão e eu coloquei os joelhos no peito dele e apertei até minhas mãos doerem e eu ver que ele estava morto. E depois apertei de novo o pescoço dele e coloquei o ouvido no peito dele para ver se o coração batia e apertei de novo e de novo e de novo e passei o resto da noite apertando o pescoço dele. Quando o dia raiou, eu o coloquei na mala e fechei a mala. [...] então peguei a mala e fiquei andando com ela na sala de um lado para o outro (OBP, p. 82).

Como se pode notar, os contos de Rubem Fonseca são permeados pela violência, seja a de um assassinato, seja a de um latrocínio, seja a de um estupro. Em Feliz Ano Novo (1993), no conto que dá nome ao livro é narrada uma história em que os três assaltantes invadem uma casa, que festejava o ano novo, em São Conrado na cidade do Rio de Janeiro. Lá eles assaltam, estupram e assassinam convidados da festa. Dois homens são assassinados somente para comprovar se ao levar um tiro próximo de uma parede o corpo ficaria preso nela:

Atirei bem no meio do peito dele, esvaziando os dois canos, aquele tremendo trovão. O impacto jogou o cara com força contra a parede. Ele foi escorregando lentamente e ficou sentado no chão. No meio do peito dele tinha um buraco que dava para colocar um panetone (FAN, p. 19).

O primeiro personagem que é assassinado não adere à parede, mas o segundo fica, pois, havia no fundo uma porta de madeira.

A violência em Rubem Fonseca não está presente somente nos acontecimentos das narrativas, mas também, no texto. O leitor sente-se violentado ao ler trechos de Fonseca. Desse modo, a violência aqui não é só vista como temática, ela é igualmente caracterizada pela linguagem, ou seja, a linguagem utilizada nas narrativas fonsequianas é portadora da violência. Os contos poderiam ser narrados da mesma forma, mas com uma descrição menos agressiva.

E não é só no que tange à violência que o leitor se sente agredido, a temática do sexo também o acomete. No romance $O$ Caso Morel (1973), Rubem Fonseca permeia a narrativa com diversos trechos com descrições minuciosas de cenas de sexo: 
Mandei Joana sentar na beira da cama de pernas abertas e comecei a beijar o seu corpo. A boceta de Joana estava fria, molhada de água, com um leve gosto de sabão. Aos poucos foi esquentando até que começou a ficar salgada. Joana deitou-se. Esticou as mãos procurando as minhas. "Entra dentro de mim... quero que você faça tudo comigo!" Joana queria ser espancada, aviltada, sodomizada, queria ter o rosto lambuzado pelo meu sêmen. Fiz a sua vontade (OCM, p. 43).

Em "Diana" conto de Ela e outras mulheres, Diana procura um homem para ter com ela um orgasmo. Na madrugada, ela encontra Manoel num café e os dois vão para o apartamento dela:

Depois de lamber seus seios e a sua vagina, eu a fui penetrando lentamente e dando uns tapas no seu rosto, sem muita força, mas mesmo assim sua face ficou vermelha. [...] Senti sua vagina ir se contraindo e logo um líquido abundante inundou o meu pênis (EOM, p. 35).

Em "Joana", do mesmo livro, o protagonista tem problemas com as suas relações sexuais, pois ele só obtém prazer com mulheres belas. Até que encontra uma mulher feia, mas atraente:

A boceta de Joana era apertada e sugante, quente, úmida. Prolonguei o mais que pude o prazer daquela penetração. Ela gozou com um ardor tão incandescente e deu um grito tão agudo que eu perdi o controle e gozei também. Confesso que foi uma das maiores trepadas da minha vida (EOM, p. 76).

O sexo é apresentado de uma forma animalizada, desenfreada que nunca sacia os personagens. Já no conto "Carpe Diem" de Histórias de amor, a descrição de uma cena de sexo entre os personagens principais é relatada com maior sutileza:

Roberto morde as bochechas de Paula, abraça o corpo dela como um urso, ela abre caminho para que ele entre no corpo dela, meu amor diz que adora foder comigo, rolam pela cama larga, ele fica em cima, ela fica em cima, diz que me ama, ele diz tudo o que ela quer que ele diga, e quando ele goza um trem de ferro passa por cima dele e ele urra como um animal ferido de morte (HA, p. 117).

Uma possível explicação para a frequente existência desta temática nos contos de Rubem Fonseca é que o sexo acaba por ser a única troca possível dos personagens, a comunicação existente entre eles. No mundo contemporâneo o sexo funciona como fuga, como alívio das tensões, bem como as bebidas e as drogas, o que seria uma espécie de recompensa. Sabendo que os personagens fonsequianos são sujeitos solitários, assim como afirma Figueiredo (2003): "Rubem Fonseca destaca, como marca da vida contemporânea, a solidão 
decorrente de dificuldade de comunicação efetiva com o outro" (p. 39).

Encerramos esta primeira parte com a citação de Barbieri (2003), sobre a imoralidade em Rubem Fonseca:

A "imoralidade" ou "incitamento" dos contos de Rubem consiste em mostrar, à luz forte de uma linguagem hiper-realista, episódios de violência moral, física, política e social, que compõem o quadro de nossa crônica diária (p. 82).

E para compor tal quadro, Fonseca utiliza-se das características que acima foram detalhadas por meio de trechos de sua obra, que são: a influência do trabalho como comissário, ou seja, os aspectos criminais existentes na obra; a linguagem crua e enxuta; utilização de diálogos; a presença da oralidade na narrativa, tanto pelos elementos e recursos gráficos; a violência no plano da narração, da linguagem, da moralidade; e da temática do sexo erótico e pornográfico.

\section{Publicações do novo século: desassociações com os primeiros escritos}

Os leitores vão acabar? Talvez. Os escritores não. $O$ escritor vai resistir.

Rubem Fonseca

Podemos perceber que no primeiro corte deste trabalho foram elencadas as principais características da narrativa fonsequiana. $\mathrm{O}$ que ora propomos é demonstrar o enfraquecimento dessas categorias em uma publicação do novo milênio, e para que isso seja realizado, respaldaremos esta etapa no penúltimo livro publicado por Fonseca, $O$ romance morreu (2007), por esse ser na sua essência uma ruptura com as publicações anteriores.

Sabemos que Rubem Fonseca escreveu de maneira mais abundante contos e romances. A publicação da análise trata-se, talvez, de um livro que reúne crônicas, ensaios, relatos de viagens e, na última parte, uma breve autobiografia. Por assim ser, $O$ romance morreu torna-se uma obra diferencial do conjunto das obras fonsequianas.

Faremos uma breve explicação sobre do que trata esse romance: Rubem Fonseca reservou para esta obra o que há de mais di- 
ferente de sua produção literária. O livro surge como um apanhado de escritos que versam ora sobre Michel Jackson, ora sobre a pele.

O primeiro texto, que dá nome ao livro, trata-se de um ensaio em que Fonseca desenvolve uma tese de que não são os autores que estão acabando e sim os leitores: "Os leitores vão acabar? Talvez. Mas os escritores não. O escritor vai resistir" (p. 10).

Em alguns ensaios podemos observar que o autor pretende esclarecer algumas de suas características ou pontos de vista, como é o caso de "A pornografia começou com a Vênus de Willendorf?", em que ele discorre sobre a presença da pornografia nas obras de arte, principalmente na literatura, assumindo a posição de favorável ao uso estilístico do tema. Assim sendo, o autor procura justificar a presença profusa da temática em suas narrativas.

O crítico e escritor Silviano Santiago em seu livro Nas malhas da letra (2002) propõe uma classificação para o narrador dos textos denominados pós-modernos. Ele considera que o narrador desta estética apresenta os fatos de outrem por ele visto ao longe e não como se os tivessem presenciado, experimentado.

Sobre esse narrador Santiago diz:

O narrador pós-moderno é o que transmite uma "sabedoria" que é decorrência da observação de uma vivência alheia a ele, visto que a ação que narra não foi tecida na substância viva de sua existência. (...) O narrador pós-moderno sabe que o "real" e o "autêntico" são construções da linguagem (p. 46).

O narrador fonsequiano não obedece a uma única forma, ou seja, ora ele se apresenta como alguém que relata o que vê, ora surge como uma pessoa que apresenta as próprias experiências, como é o caso dos narradores de $O$ romance morreu. Em "Reminiscências de Berlim", Fonseca relata sua passagem pela Alemanha no período da queda do muro: "Eu morava em Berlim, no lado ocidental, havia alguns meses, na rua Storkwinkel 14, um apartamento confortável que me foi cedido pela Deutscher Akademischer Austauschdienst" (p. $62)$.

Já em "Desventuras de um dendólatra", o autor narra sua preocupação com as árvores e o seu desejo de protegê-las, como podemos perceber os narradores em esses dois exemplos são participantes 
do que narram. A revista Bravo!, publicada em novembro de 2009, diz que esse conto auxilia a compreensão da vida pessoal do autor, tendo em vista que Fonseca, bem como o narrador, assume-se como um protetor das árvores.

Deonísio da Silva (1996), defende a ideia de que esse narrador participante do narrado é um alter ego de Fonseca:

A opção por uma narrativa em primeira pessoa do singular - predominância absoluta na ficção do autor - revela um recurso estratégico de extraordinário vigor para a ficção documental e testemunhal de Rubem Fonseca, além de cindir, vertical e profundamente, a ficção de cunho social, levando aquele que narra a ser um dos rebelados que se junta aos personagens, personagem ele também, ao mesmo tempo em que conduz a narrativa (p. 51).

Assim sendo, conforme Santiago, podemos constatar que a forma como o narrador ao leitor apresenta o livro está ainda presa nos moldes pós-modernos. Podemos dizer que nesse item não foi verificada nenhuma mudança significativa da estética fonsequiana.

Como foi visto, Rubem Fonseca preencheu sua obra com os aspectos criminais procedentes do seu contato com a delegacia. Em $O$ romance morreu esse mundo subversivo é abandonado. Nesse seu último romance não há nenhuma referência ao submundo da violência e do crime, o que já é um suposto sintoma de uma pequena ruptura com os primeiros escritos.

Uma característica bastante acentuada nos romances pósmodernos, incluindo-se os de Rubem Fonseca, é a temática da violência. Praticamente todas as obras fonsequianas são permeadas pela violência urbana desenfreada. Essa peculiaridade foi extinta dos escritos de $O$ romance morreu, por não existir nenhuma referência brutal ou crua à violência. Esse é outro aspecto relevante da obra. Podemos dizer que este esvaziamento temático, que antes era constante, torna-se um estigma do livro analisado e um sinal de que realmente há uma diferença na essência desta obra de Fonseca. Pode haver aqui alguma reação a anterior violência desenfreada que permeava a obra desse autor.

Outra presença inalterável nas narrativas fonsequianas é a temática do sexo pornográfico representado sem nenhum resguardo e 
pudor. A falta de reservas nesse ponto foi totalmente preterida, não há nenhum resquício desse em $O$ romance morreu.

Já no que consta ao uso dos excessivos palavrões há um esgotamento bastante significativo. Há uma única ocorrência na obra: "Trinta - trinta, puta que pariu! -, trinta oportunidades de gol perdidas pelo nosso time" (p. 107). Este palavrão em relação aos outros não tem a menor significância.

Outra característica que ainda aparece nesta obra é a linguagem crua e enxuta sem rodeios ou metáforas. Essa é uma marca estilística do autor que não perde o seu vigor e que permanece sem nenhuma alteração.

Quiçá o texto mais importante dessa coletânea seja o último "José - uma história em cinco capítulos" - em que Rubem Fonseca parece escrever sua biografia, regressando a sua infância no estado de Minas Gerais até chegar ao Rio de Janeiro. Relato bastante verossímil e de grande suporte para uma breve compreensão da vida do autor. O narrador, em que se esconde o autor, relata que suas memórias não são perfeitas e que depende muito da criação poética para recriá-las:

Ao falar de sua infância, José tem de recorrer à sua memória e sabe que ela o traiu, pois muita coisa está sendo relembrada de maneira inexata ou foi esquecida. Porém ficou claro para ele que, na verdade, a memória pode ser aliada da vida (p. 162).

Pelo exposto podemos perceber que houve uma significativa quebra na seleção do gênero escolhida por Fonseca para a publicação de $O$ romance morreu. Sabemos que o autor tem preferência por escrever contos, romances e novelas, porém esse livro de análise abandona esses gêneros e serve-se do relato e da crônica.

Já é bastante expressiva a alteração que há no gênero e somase a essa mutação a ausência da violência, do sexo e dos palavrões. Tudo sempre foi a principal cicatriz da obra fonsequiana.

Todas as alterações temáticas percebidas foram desvinculadas da proposta pós-moderna que frequentaram as publicações, do mesmo autor, anteriores a 2007. Não podemos ainda definir se a escolha será definitiva, ou ainda concreta. Após estudos sobre outros romances, poderemos chegar a novas conclusões e colaborar para um es- 
clarecimento mais amplo a propósito do enfraquecimento da estética pós-modernista nos romances do novo século. Dessa forma esta pesquisa ficará em aberto para novas e recentes contribuições, tanto do campo teórico, quanto do ficcional.

\section{REFERÊNCIAS BIBLIOGRÁFICAS}

ARISTÓTELES. A poética clássica. São Paulo: Cultrix, 2007.

BARBIERE, Therezinha. Ficções impuras. Prosa brasileira dos anos 70, 80 e 90. Rio de Janeiro: Eduerj, 2003.

BOSI, Alfredo. História concisa da literatura brasileira. 43. ed. São Paulo: Cultrix, 2007.

CANDIDO, Antonio. A educação pela noite \& outros ensaios. São Paulo: Ática, 1987.

ECO, Umberto. Como se faz uma tese. São Paulo: Perspectiva, 2008.

FIGUEIREDO, Vera Lúcia Follain de. Os crimes do texto: Rubem Fonseca e a ficção contemporânea. Belo Horizonte: UFMG, 2003.

FONSECA, Rubem. O caso Morel. Rio de Janeiro: Arte Nova, 1973. 1987. . Lúcia McCartiney. 6. ed. Rio de Janeiro: Francisco Alves, . Feliz Ano Novo. São Paulo: Cia. das Letras, 1993. . O buraco na parede. São Paulo: Cia. das Letras, 1995. . Histórias de amor. São Paulo: Cia. das Letras, 1997. . 64 contos de Rubem Fonseca. São Paulo: Cia. das Letras, 2005. . Ela e outras mulheres. São Paulo: Cia. das Letras, 2006. . O romance morreu. São Paulo: Cia. das Letras, 2007.

LAJOLO, Marisa; ZILBERMAN, Regina. A formação da leitura no Brasil. São Paulo: Ática, 1996. 
MARTÍNEZ, Tomás Eloy. A sinfonia do mal. In: FONSECA, Rubem. 64 contos de Rubem Fonseca. São Paulo: Cia. das Letras, 2005, p. 9-14.

MÓISES, Massaud. A literatura brasileira através dos textos. 25. ed. São Paulo: Cultrix, 2005.

PETRIK, Tiago; PORTO, Malu; Lima, João Gabriel de. O personagem Rubem Fonseca. Bravo! São Paulo, novembro de 2009, n. 147, p. 30-42.

SANTIAGO, Silviano. Nas malhas da letra. Rio de Janeiro: Rocco, 2002.

SILVA, Deonísio. Rubem Fonseca: Proibido e consagrado. Rio de Janeiro: Relume-Dumará, 1996.

URBANO, Hudinilson. Oralidade na literatura: O caso Rubem Fonseca. São Paulo: Cortez, 2000.

VALENTE, Luiz Fernando. Entre o Clio e o Calíope: a construção da narrativa histórica em Os sertões. História, ciências e saúde. Rio de Janeiro: Fundação Oswaldo Cruz, v. V, 1997, p. 39-55.

VIEGAS, Ana Cristina Coutinho. Rubem Fonseca e a difícil arte de criar leitores. Terceira Margem: Revista da Pós-graduação em Letras. Rio de Janeiro: UFRJ, ano IV, n. 4, 1996, p. 130- 130. 